\section{Response to: 'Interosseous tendon inflammation of rheumatoid arthritis: what's the real meaning?' by Deng et al}

We thank Deng for their interest in our study, ${ }^{1}$ in which we identified MRI interosseous tendon inflammation (ITI) in anticyclic citrullinated peptide positive at-risk individuals (CCP+ at risk) without clinical synovitis. ${ }^{2}$ Given the MRI appearances and absence of a tendon sheath on histological examination, we suggested ITI is a peritendonitis rather than a tenosynovitis. ITI was originally described as a tenosynovitis by Rowbotham et al. ${ }^{3}$ However, in the discussion, it was acknowledged that this may not be the correct terminology as the MRI features were not typical of tenosynovitis and the microstructure of the tendons had not been well described. ${ }^{3}$ Indeed, it was conceded that ITI may be better described as peritendinous inflammation or 'paratenonitis' rather than a true tenosynovitis. The lack of a tendon sheath demonstrated in the current study certainly supports this assertion.

We were interested in the view that ITI represents a fasciitis, which may be considered an extra-articular manifestation of rheumatoid arthritis (RA), similar to rheumatoid lung or rheumatoid vasculitis. ${ }^{1}$ We agree that ITI, like these other features, may be viewed as an extra-articular consequence of RA autoimmunity. However, other extra-articular manifestations in RA are not periarticular and have different associations, generally seen in the setting of longstanding joint disease with increased prevalence in males and smokers. ${ }^{4}$ They are also very unusual to find in at-risk individuals prior to the development of arthritis. Instead, ITI appears to frequently precede arthritis and occurs adjacent to the metacarpophalangeal joints, raising important questions about its role in the development of RA.

Although, to the best of our knowledge, the current study is the largest MRI study in CCP+ at-risk individuals, we agree larger studies should be done to confirm our findings. We also agree that ITI may not be specific to RA, and may be associated with mechanical factors or other conditions; we could not assess these factors in our study and acknowledged this in the discussion of the manuscript. Deng questioned whether the results could be gender-biassed as our subjects were predominantly female. ${ }^{1}$ However, RA is more frequent in females, with a sex ratio of around 3:1. As such, we aimed to describe ITI and its associations in a population representative of the condition of interest rather than the general population. Similarly, the mean age of the RA patients included in our study was between 50 and 60 years, which is representative of the RA demographic. ${ }^{5}$ Whether ITI is as prevalent in different age groups is an interesting question, which could be addressed in future work.

In describing histological findings, we followed the histological terminology of the Federative International Committee on Anatomical Terminology (2008). ${ }^{6}$ We regret that some of the abbreviations were accidentally omitted from the figure legend (EM, endomysium; EPM, epimysium; MF, muscle fascicles).

Finally, we agree that it would be interesting to know if peritendinous inflammation or fasciitis is a generalised phenomenon found at other sites in symptomatic at-risk individuals. For example, CCP+ at-risk individuals often present with foot pain without synovitis ${ }^{7}$ and it is possible that extracapsular inflammation may be responsible. Further imaging studies would certainly be useful in this regard.

Kulveer Mankia $\odot,^{1,2}$ Maria-Antonietta D'Agostino, ${ }^{3}$ Jorge Murillo-González, ${ }^{4}$ Andrew Grainger, ${ }^{5,6}$ Paul Emery $\odot^{7,8}$

${ }^{1}$ Leeds Institute of Rheumatic and Musculoskeletal Medicine, University of Leeds, Leeds, UK

${ }^{2}$ NIHR Leeds Biomedical Research Centre, Leeds Teaching Hospitals NHS Trust, Leeds, UK

${ }^{3}$ Rheumatology, Ambroise Paré Hospital, APHP, Université Versailles-Saint-Quentin en Yvelines, Boulogne-Billancourt, France

${ }^{4}$ Anatomy and Emryology, Universidad Complutense de Madrid, Madrid, Spain

${ }^{5}$ Department of Radiology, Leeds Teaching Hospitals NHS Trust, University of Leeds, Leeds, UK

${ }^{6}$ NIHR Leeds Biomedical Research Centre, Leeds Teaching Hospitals NHS Trust, Leeds, UK

${ }^{7} 1$ Leeds Institute of Rheumatic and Musculoskeletal Medicine, Leeds, UK

${ }^{8}$ Leeds Teaching Hospitals NHS Trust, 2 NIHR Leeds Musculoskeletal Biomedical Research Unit, Leeds, UK

Correspondence to Dr Kulveer Mankia, Leeds Institute of Rheumatic and Musculoskeletal Medicine, University of Leeds, Leeds LS7 4SA, UK;

k.s.mankia@leeds.ac.uk

Handling editor Josef S Smolen

Funding This research has received no specific grant from any funding agency in the public, commercial or not-for-profit sectors.

Competing interests None declared.

Patient consent for publication Not required.

Provenance and peer review Commissioned; internally peer reviewed.

(c) Author(s) (or their employer(s)) 2020. No commercial re-use. See rights and permissions. Published by BMJ.

\section{Check for updates}

To cite Mankia K, D'Agostino M-A, Murillo-González J, et al. Ann Rheum Dis 2020;79:e84.

Received 9 May 2019

Accepted 9 May 2019

Published Online First 17 May 2019

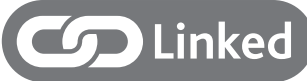

- http://dx.doi.org/10.1136/annrheumdis-2019-215559

Ann Rheum Dis 2020;79:e84. doi:10.1136/annrheumdis-2019-215611

\section{ORCID iDs}

Kulveer Mankia http://orcid.org/0000-0002-7945-6582

Paul Emery http://orcid.org/0000-0002-7429-8482

\section{REFERENCES}

1 Deng ZL, Lu W. Interosseous tendon inflammation of rheumatoid arthritis: what's the real meaning? Ann Rheum Dis 2020;79:e83.

2 Mankia K, D'Agostino M-A, Rowbotham E, et al. MRI inflammation of the hand interosseous tendons occurs in anti-CCP-positive at-risk individuals and may precede the development of clinical synovitis. Ann Rheum Dis 2019;78:781-6.

3 Rowbotham EL, Freeston JE, Emery P, et al. The prevalence of tenosynovitis of the interosseous tendons of the hand in patients with rheumatoid arthritis. Eur Radiol 2016;26:444-50.

4 Young A, Koduri G. Extra-articular manifestations and complications of rheumatoid arthritis. Best Pract Res Clin Rheumatol 2007;21:907-27.

5 Innala L, Berglin E, Möller B, et al. Age at onset determines severity and choice of treatment in early rheumatoid arthritis: a prospective study. Arthritis Res Ther 2014;16.

6 Terminologia Histologica. International terms for human cytology and histology by the Federative International Committee on anatomical terminology (FICAT. Philadelphia: Wolters Kluwer/Lippincott Williams \& Wilkins.

$7 \mathrm{Nam}$ JL, Hunt L, Hensor EMA, et al. Enriching case selection for imminent RA: the use of anti-CCP antibodies in individuals with new non-specific musculoskeletal symptoms - a cohort study. Ann Rheum Dis 2016;75:1452-6. 